Bull. Mater. Sci., Vol. 36, No. 6, November 2013, pp. 989-996. (c) Indian Academy of Sciences.

\title{
Preparation and properties of polyrotaxane from $\alpha$-cyclodextrin and poly(ethylene glycol) with poly(vinyl alcohol)
}

\author{
MOHAMMAD ALI SEMSARZADEH* and SAHAR AMIRI \\ Polymer Group, Chemical Engineering Department, Tarbiat Modares University, Tehran, Iran
}

MS received 4 May 2012

\begin{abstract}
Cyclodextrin ( $\alpha$-CD) was found to form inclusion complexes with poly(ethylene glycol) (PEG) having a crystalline state in high yields, which have been investigated extensively in the past. Formation of an inclusion complex depends strongly on structure, molecular weight and geometry of the polymer. Development of a dicomponent inclusion complex (DIC) of PEG and $\alpha$-CD in the presence of poly(vinyl alcohol) (PVA) and initiation of hexagonal crystals upon sonication have exhibited various microstructures. Formation of the new inclusion complex in PVA heavily depends on the concentration of PVA, temperature and sonication time. The complexes produced are characterized by FTIR, HNMR spectra and powder X-ray. ${ }^{1}$ HNMR of the complexes demonstrate that their stoichiometric ratio is 2:1 (two ethylene glycol units and one $\alpha$-CD). X-ray patterns of PEG- $\alpha$-CD complex indicate that the $\alpha$-CD forms channels whereas PEG/ $\alpha-\mathrm{CD} / \mathrm{PVA}$ creates cage-type structures.
\end{abstract}

Keywords. Cyclodextrin; poly(ethylene glycol); poly(vinyl alcohol); sonication; hexagonal microstructures.

\section{Introduction}

Poly(ethylene glycol) and cyclodextrins, as two thermodynamically homogeneous solutions, are both soluble in water. Poly(ethylene glycol) makes a reversible complex inclusion compound with $\alpha$-cyclodextrin (Harada et al 1993; Ooya et al 2007). Meanwhile, cyclodextrins (CDs) are a series of natural cyclic oligosaccharides composed of 6,7 or $8 \mathrm{D}(+)$ glucose units, which are connected through $\alpha$-1,4-bondings viz. $\alpha-, \beta$ - or $\gamma$-CD, respectively. The doughnut-shaped geometry of CDs gives a hydrophobic inner cavity having a depth of $\sim 7.0 \AA$ and internal diameters of $\sim 4.5,7.0$ and $8.5 \AA$ for $\alpha$-, $\beta$ - and $\gamma$-CD, respectively. Various molecules can be fitted into the cavities of CDs to form supramolecular inclusion complexes, which have been widely studied as models to explain the mechanism of molecular identification (Bender and Komiyama 1978; Szejtli 1982, 1998). Recently, poly-pseudorotaxanes or ICs with necklace-like supramolecular structures formed using cyclodextrins and polymers have attracted special interest (Horter and Dressman 1997; Duchene et al 1999; Hirayama and Uekama 1999; Loftssona and Jarvinen 1999; Matsuda and Arima 1999; Szente and Szejtli 1999). It has been discovered that the correlation between cross-sectional areas of the polymer chains and cavity sizes of CDs plays a key role in IC formation.

Inclusion complex of polymers containing CDs has been investigated by Harada et al (1993). However, there is not much information about the reactions between CD and PVA.

\footnotetext{
*Author for correspondence (semsarzadeh@modares.ac.ir)
}

The current work aims to prepare and examine regularly shaped, hexagonal complexes of $\alpha-\mathrm{CD}$ using PEG in the presence of PVA. The sonic energy was found to have major effect on the formation of discrete-size microcrystals for complex inclusion compounds of PEG- $\alpha$-CD in PVA solution. Both the time and sonic energy at room temperature $\left(25^{\circ} \mathrm{C}\right)$ were effective factors of this process. The right concentration of PVA could facilitate the formation of discrete hexagonal microcrystals. The effect of PVA and its solution viscosity on both reaction and ionic environment contributes to the new morphology, which controls size of the crystalline microstructures. Microcrystals might be formed at longer sonication times. In the absence of sonication or PVA, the inclusion compounds tend to be randomized without discrete hexagonal crystals being created. Production of discrete crystals in PVA has not been reported before. Complex crystals can be used in drug delivery systems because of their ability to enhance drug delivery through biological membranes in addition to separation processes, HPLC and gas chromatography (GC). CDs are capable of forming inclusion complexes in pharmaceutics, analytical sciences, separation processes (e.g. for environmental protection) and catalysis, as well as cosmetic, textile, food and packaging industries. For instance, in pharmaceutics, CDs have primarily entered as solubilizers for lipophilic drugs in order to enhance their bioavailability and/or to reduce their adverse effects after oral, parenteral or other administration techniques. Having administered a drug/CD complex, its dissociation would lead it to be released in relevant body compartments, mediated by dilution effects and competitive replacement using tissue/serum components (e.g. lipids or cholesterol). Thus, research in this area is extremely important. 
Table 1. Conversion of ( $\alpha$-CD/PEG) without sonication at different times and temperatures.

\begin{tabular}{lllll}
\hline \multirow{2}{*}{$\begin{array}{l}\text { Time of } \\
\text { reaction }\end{array}$} & \multicolumn{3}{c}{ Temperature } & \multicolumn{3}{c}{ Conversion of $\alpha$-CD+PEG without sonication (\%) } \\
\cline { 2 - 5 } $1 \mathrm{~h}$ & $0{ }^{\circ} \mathrm{C}$ & $25^{\circ} \mathrm{C}$ & $40{ }^{\circ} \mathrm{C}$ & $50{ }^{\circ} \mathrm{C}$ \\
\hline $\mathrm{h}$ & 46 & 32 & 30 & - \\
$3 \mathrm{~h}$ & 49 & 43 & 39 & - \\
$4 \mathrm{~h}$ & 51 & 48 & 42 & 41 \\
\hline
\end{tabular}

\section{Experimental}

\subsection{Material}

Poly(ethylene glycol) 1000 (PEG 1000), poly(vinyl alcohol) 72000 (PVA 72000), $\alpha$-cyclodextrin ( $\alpha$-CD content $>$ $98 \%)$ and phosphate buffer were purchased from Merck, Applichem.

\subsection{Characterization}

Polyrotaxanes were dissolved in $\mathrm{CDCl}_{3}$ and characterized by $400 \mathrm{MHz}{ }^{1} \mathrm{HNMR}$ spectroscopy (DRX 400 Bruker Avance) at ambient temperature. Polymer concentration in the $\mathrm{CDCl}_{3}$ solution was about $2 \mathrm{w} / \mathrm{v} \%$. Fourier transform infrared (FTIR) spectrum of the polyrotaxanes (solids) was recorded on an EQUINOX 55 Bruker FTIR Spectrophotometer. X-ray diffraction (XRD) was used to study the diffraction patterns of PVA $/ \alpha-\mathrm{CD} / \mathrm{PEG}$ crystals at ambient conditions; an Xpert Philips diffractometer (USA) with nickel filtered $\mathrm{CuK} \alpha$ radiation was used in this work. Data were collected at a rate of ${ }^{\circ} 2 \theta$ min over the $5 \approx 60^{\circ}$ range of $2 \theta$ (Ohmura et al 2004; Choi et al 2005; Kawasaki et al 2007; Loftssona and Duchene 2007). Scanning electron microscopy (SEM), Philips XL30 (Poland), was used to study the Aucoated microstructures of complexes. Differential scanning calorimetry (DSC) curves of the samples were recorded on a differential scanning calorimeter at $-100-250{ }^{\circ} \mathrm{C}$ at a scanning rate of $10^{\circ} \mathrm{C} \mathrm{min}^{-1}$. The measurements were performed on $5 \mathrm{mg}$ of the sample in closed aluminium containers in a nitrogen atmosphere.

\subsection{Complex formation of $\alpha-C D / P E G$ without sonic energy}

The inclusion complexes of $\alpha$-CD and PEG were prepared by adding an aqueous solution of PEG $(5.0 \mathrm{~mL}$ of $5.0 \mathrm{wt} \%)$ to the aqueous solution of $\alpha-\mathrm{CD}(5.0 \mathrm{~mL}$ of $14.5 \mathrm{wt} \%)$ followed by mixing for $1,2,4$ and $6 \mathrm{~h}$ at $0,25,40$ and $50{ }^{\circ} \mathrm{C}$ (table 1 ). These inclusion complexes were then separated using filtration techniques and redissolved in phosphate buffers at $\mathrm{pH}=7-9$ at room temperature (Harada et al 1993; Crini and Morcellet 2003; Araki et al 2004; Son et al 2006; Ooya et al 2007).
Table 2. Conversion of $(\alpha-\mathrm{CD} / \mathrm{PEG})$ with sonication at room temperature.

\begin{tabular}{rcc}
\hline \multicolumn{2}{l}{ Sonication time } & \\
& Concentration of $(\alpha-\mathrm{CD}+\mathrm{PEG})$ & \\
\hline $5 \%$ & $15 \mathrm{~min}$ & $30 \mathrm{~min}$ \\
$15 \%$ & $21 \%$ & $51 \%$ \\
$20 \%$ & $23 \%$ & $64 \%$ \\
& $32 \%$ & $82 \%$ \\
\hline
\end{tabular}

\subsection{Production of PEG $/ \alpha-C D$ in $P V A$}

The new complex of $\alpha$-CD/PEG in PVA was first developed from PEG and $\alpha$-CD under sonic energy (table 1). Afterwards, the sonicated complex was dissolved in an aqueous solution of PVA $(5 \cdot 0,10,15$ and $20 \mathrm{wt} \%)$ at room temperature and stirred for $1 \mathrm{~h}$ at $50{ }^{\circ} \mathrm{C}$. The solution was finally centrifuged and kept for 1 day to form the new complex. Finally, the solid complex was easily separated by dissolving in water to cast films.

\section{Results and discussion}

\subsection{Preparation of complexes}

CDs are threaded onto polymer chains in order to give the inclusion complexes, especially when the polymer is hydrophobic in comparison with the solvent. Selective threading might occur when the polymer structure contains both hydrophobic and hydrophilic segments. Meanwhile, $\alpha$-cyclodextrin forms crystalline inclusion complexes with PEG. The complexes were isolated by filtration or centrifugation, rinsed with water and dried. Table 1 summarizes yields of the complexes for $\alpha$-CD with PEG at various temperatures and times. The yields are calculated on the basis of a 2:1 (ethylene glycol unit: $\alpha$-CD) stoichiometry. It can be observed that the yields rise with an increase in either reaction time or temperature (table 2). The complexes were obtained almost quantitatively with PEG of over 1000 molecular weight. Although PEG of this molecular weight has made complexes with $\alpha$-CD slowly, these complexes gave 

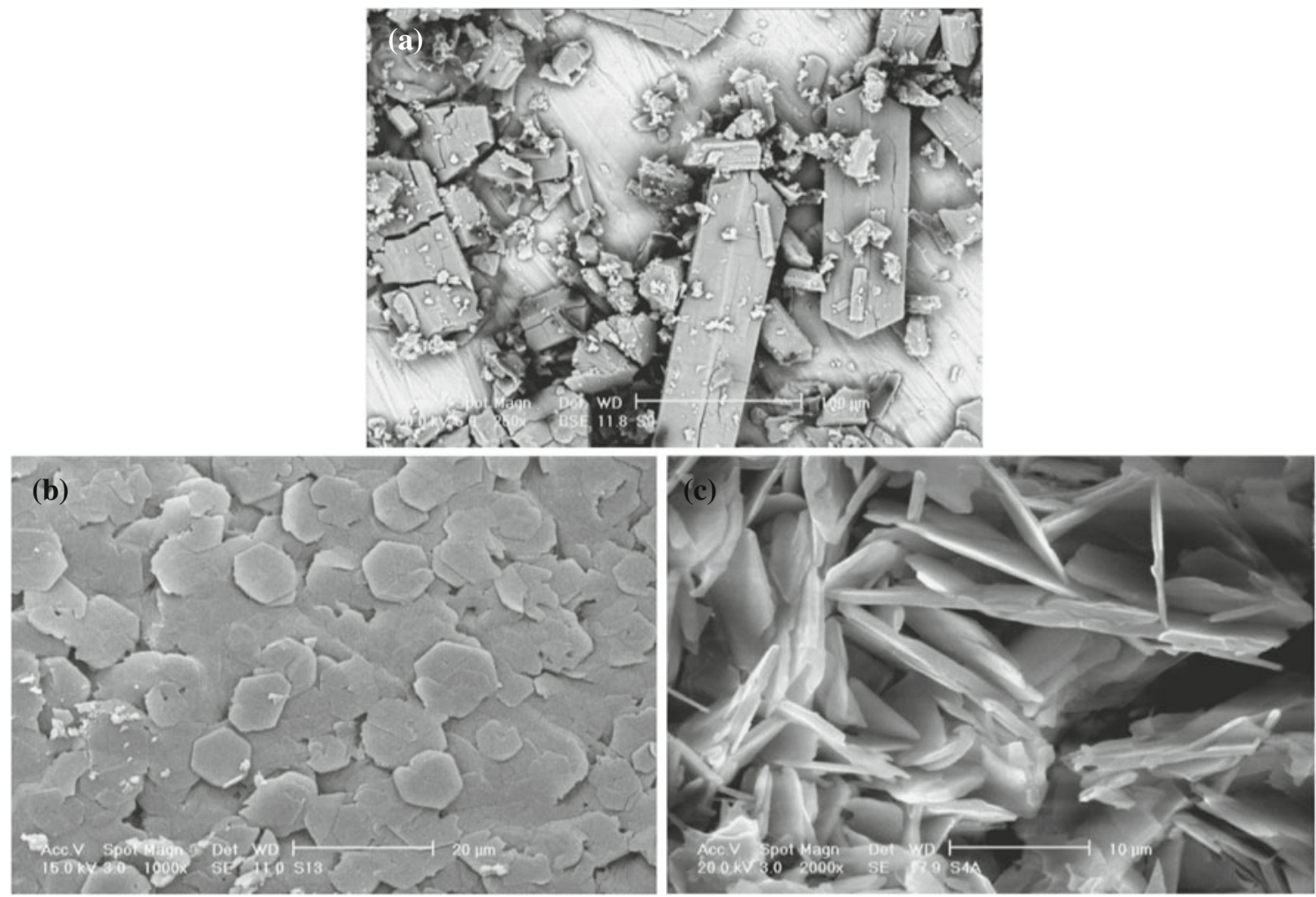

Figure 1. SEM images of prepared $\alpha-\mathrm{CD}$ and $\alpha-\mathrm{CD} / \mathrm{PEG}$ inclusion compounds: (a) $\alpha-\mathrm{CD}$, (b) $2 \mathrm{~h}$ at $0{ }^{\circ} \mathrm{C}$ at $\mathrm{pH}=7$ and (c) $4 \mathrm{~h}$ at $25^{\circ} \mathrm{C}$ at $\mathrm{pH}=7$.

high yields (51-55\%) after $4 \mathrm{~h}$. The crystalline morphologies of $\alpha-\mathrm{CD}$ and $\alpha-\mathrm{CD} / \mathrm{PEG}$ are depicted in figure 1 .

\subsection{Properties of produced complexes}

The complexes of $\alpha$-CD with PEG of low molecular weight (1000) are soluble in a large amount of water. The complexes of PEG having high molecular weight can be dissolved in water upon heating (Saenger 1980; Peng et al 2007; Semsarzadeh et al 2007; Hirose and Otsubo 2008). It is obvious that the formation of this complex is reversible. Complexes of the solution are in equilibrium with their components. Hydrogen bonding plays an important role in the formation of the complexes between PEG and $\alpha-\mathrm{CD}$. The resultant complexes are dissolved in boiling water and they can be reproduced by cooling to $0{ }^{\circ} \mathrm{C}$.

The IR spectra of PEG, $\alpha$-CD and inclusion complex of $\mathrm{PEG} / \alpha-\mathrm{CD}$ are shown in figure 2 . IR spectrum of PEG showed the $\mathrm{C}-\mathrm{O}$ stretching band $\left(1110 \mathrm{~cm}^{-1}\right)$ of PEG. The key feature in this spectrum is the absorption due to the symmetric $\mathrm{C}-\mathrm{H}$ deformation modes of methyl groups at $1263 \mathrm{~cm}^{-1}$. FTIR of inclusion complex of PEG/ $\alpha-\mathrm{CD}$ showed presence of the ' $\mathrm{OH}$ ' absorption band at about 3542.5 and $3853 \mathrm{~cm}^{-1}$, the ' $\mathrm{CH}$ ' band at about 2853 and $2854 \mathrm{~cm}^{-1}$, the ' $\mathrm{C}=\mathrm{O}$ ' absorption band at about 1732 and $1811 \mathrm{~cm}^{-1}$ and the ' $\mathrm{C}=\mathrm{C}$ aromatic' absorption band at about $1560 \mathrm{~cm}^{-1}$.

\subsection{Binding mode of complex}

XRD spectra of the modified PEG, $\alpha-\mathrm{CD}$ and IC of PEG $/ \alpha-$ $\mathrm{CD}$ are shown in figure 3. Saenger et al reported that the structures of inclusion complexes in CDs with low molecular weight compounds can be classified into two groups, viz. 'cage type' and 'channel type' (Saenger 1980; Peng et al 2007; Semsarzadeh et al 2007; Hirose and Otsubo 2008). The powder X-ray pattern of the $\alpha$-CD/PEG complex uncovers that these complexes are crystalline with extended column structure being reported for them, which is rather different from those of the complexes with small cage-type molecules. The results show that $\alpha$-CD/PEG complexes are isomorphous with typical 'channel type' structure instead of the so-called 'cage type' structure. Comparison of the peaks showed that the crystal had changed. The prominent crystal peaks of PEG appeared at $2 \theta=19.6^{\circ}$ and $23.2^{\circ}$, while in ICs, a new strong peak appeared at $2 \theta=19.9^{\circ}$, which was the characteristic peak of ICs associated with a channeltype crystalline structure by virtue of the polymeric nature of the guest molecules (Peng et al 2007). This result showed that $\alpha$-CDs were threaded in the PEG chains and stacked to produce ICs.

Figure 4 shows ${ }^{1} \mathrm{HNMR}$ spectrum of PEG and the inclusion complex between $\alpha$-CD/PEG with a molecular weight of 1000 . The signal at $3.5 \mathrm{ppm}$ was the protons of $\mathrm{OCH}_{2} \mathrm{CH}_{2}$ in the PEG. The proton signals of $\alpha$-CDs were localized from 3 to $6 \mathrm{ppm}$. $\alpha$-CD involves a less symmetrical conformation 

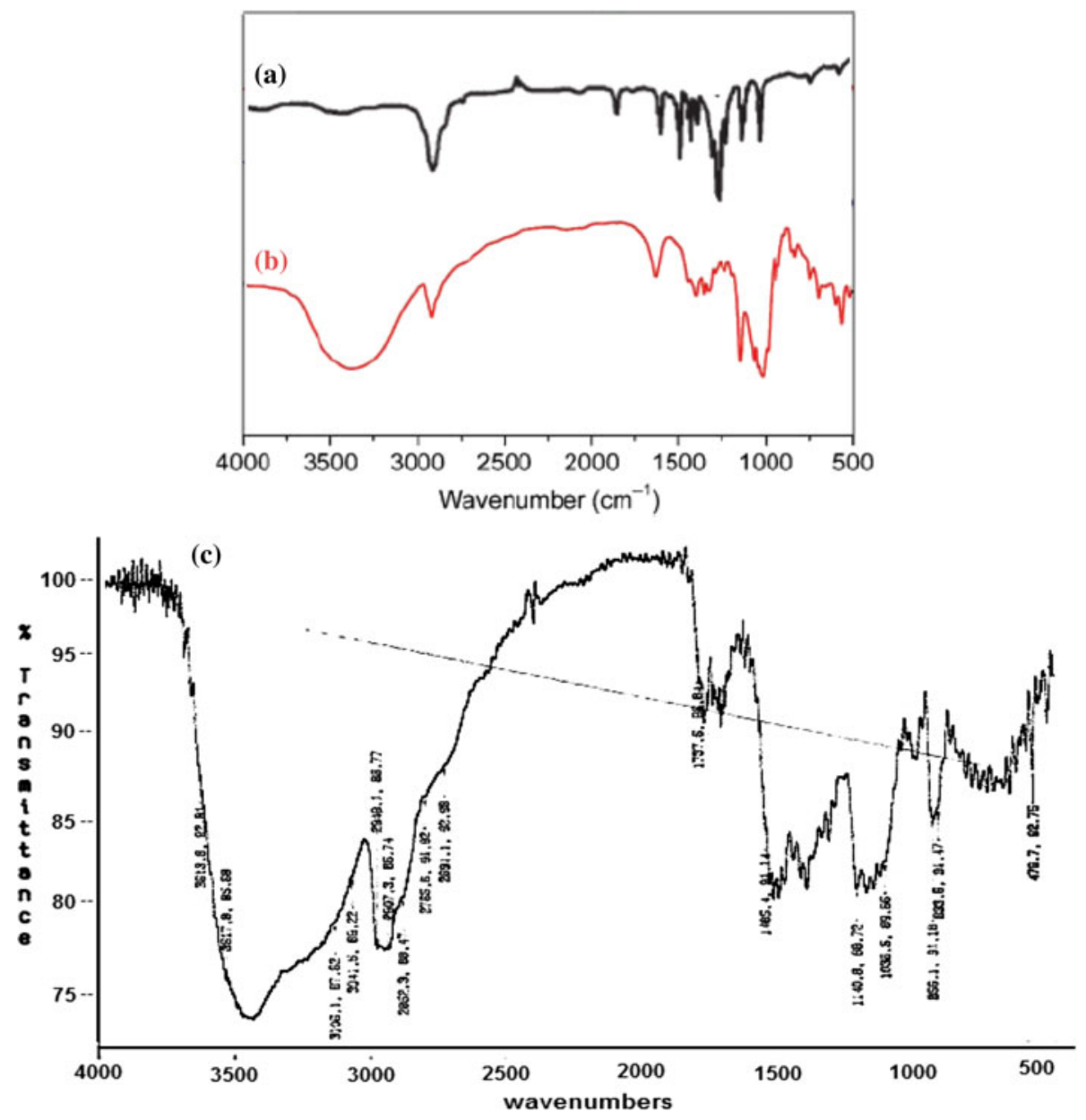

Figure 2. FTIR spectra of complexes of (a) PEG ( $m=1000)$, (b) $\alpha$-CD and (c) IC of $\mathrm{PEG} / \alpha-\mathrm{CD}$.

in the crystal with not a guest in the cavity (Harada et al 1993, 1995). Comparison of the integral for the CD $(1 \mathrm{H})$ peak and that of the methyl group on PEG introduces two monomer units, which bind to the $\alpha$-CD. It should be noted that the stoichiometric ratios are always constant at 2:1 (monomer unit:CD), regardless of the ratios for CD and PEG (Saenger 1980).

FTIR spectra of the $[\alpha-\mathrm{CD} / \mathrm{PEG}] / \mathrm{PVA}$ is shown in figure 5. FTIR spectra of this compound shows presence of the 'OH' absorption band at about 3542.5 and $3853 \mathrm{~cm}^{-1}$, the ' $\mathrm{CH}$ ' band at about 2853 and $2854 \mathrm{~cm}^{-1}$, the ' $\mathrm{C}=\mathrm{O}$ ' absorption band at about 1732 and $1811 \mathrm{~cm}^{-1}$ and the ' $\mathrm{C}=\mathrm{C}$ aromatic' absorption band at about $1560 \mathrm{~cm}^{-1}$ for $[\alpha-\mathrm{CD} /$ PEG]/PVA complexes.

\subsection{Complex of $\alpha-C D / P E G$ in PVA}

The effect of PVA on crystal lattice of $\alpha-C D$ and poly(ethylene glycol) has not been reported. In this work, the effect of sonication on crystal formation revealed that a

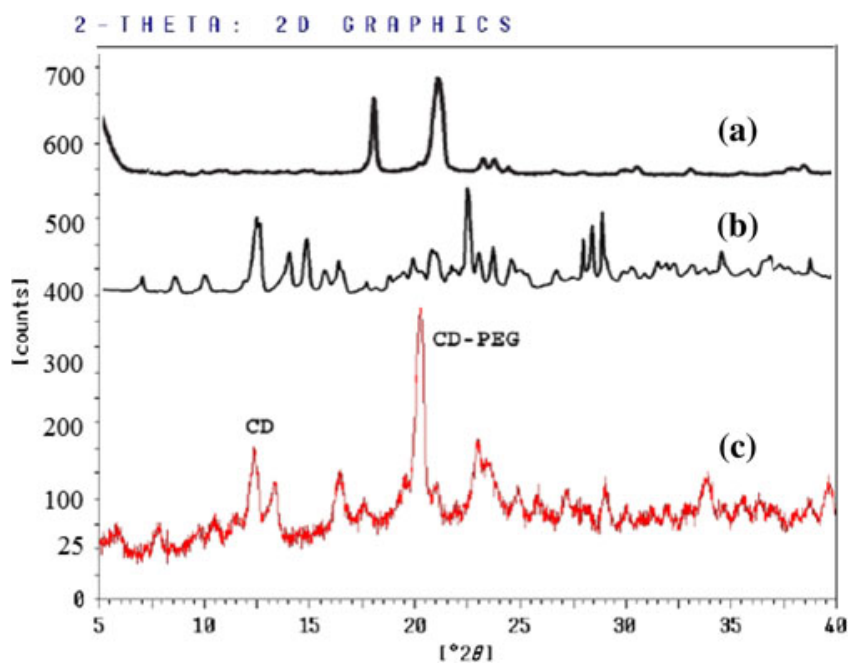

Figure 3. X-ray powder patterns of complex of (a) PEG, (b) $\alpha$ $\mathrm{CD}$ and (c) inclusion complex of $\alpha-\mathrm{CD}$ and PEG. 


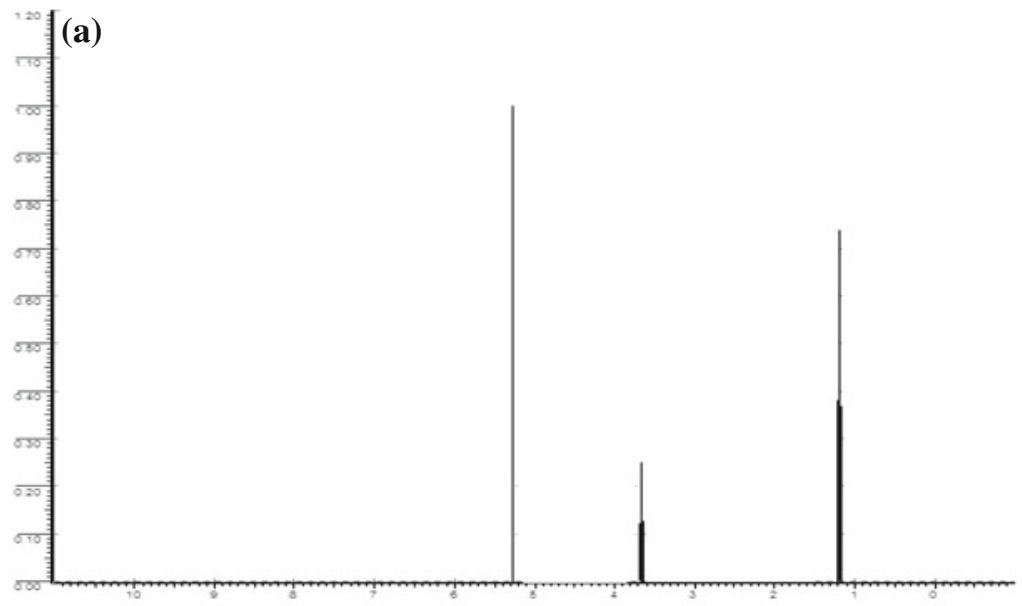

(b)

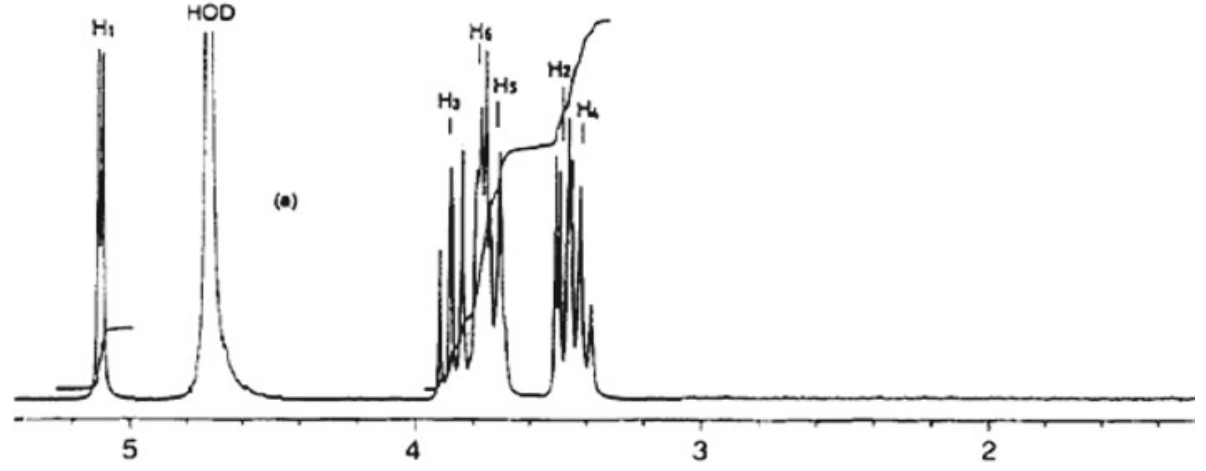

Figure 4. ${ }^{1} \mathrm{H}$ NMR spectra of complexes of (a) PEG and (b) IC of PEG/ $\alpha-\mathrm{CD}$.

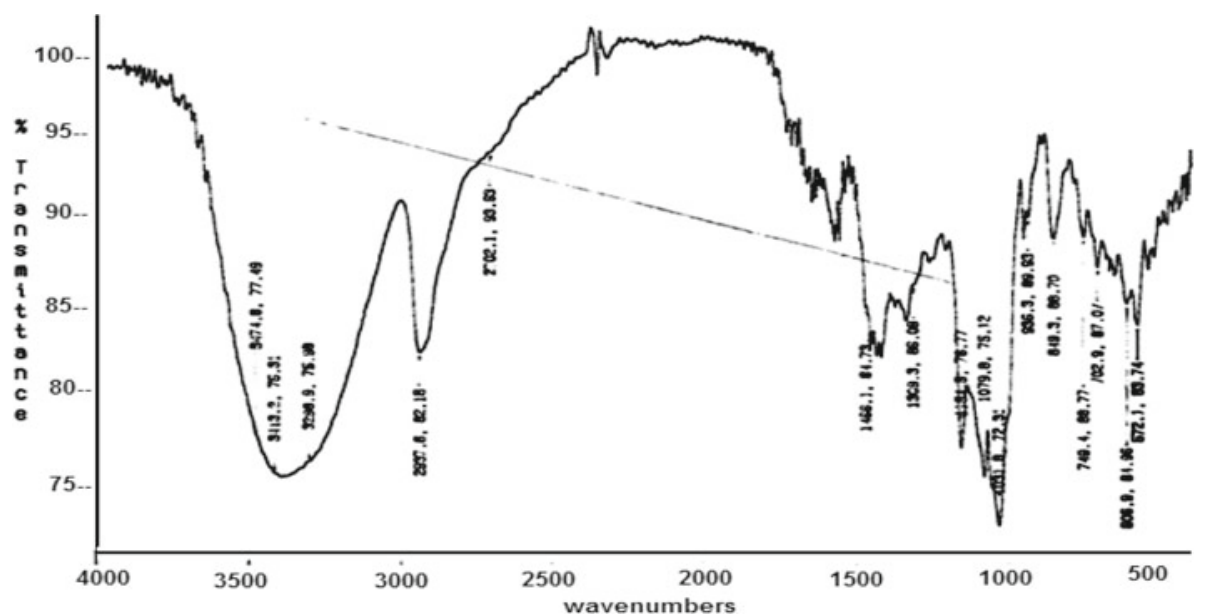

Figure 5. FTIR spectra of complexes of PVA (5\%) and $[\alpha-\mathrm{CD} / \mathrm{PEG}](20 \%)$.

longer sonication time of at least $30 \mathrm{~min}$ is required for complete crystallization. Under this condition, discrete hexagonal crystals are formed with PVA concentration of $5 \mathrm{wt} \%$ in $20 \mathrm{wt} \%$ of $\alpha$-CD/PEG. The newly formed crystals are shown in figure 6.

Major XRD peaks of the complex in PVA have been listed in table 3 at different sonication times. The effect of sonication time on the microstructure of the complex is depicted in figure 7. This figure shows that apart from sonication time (30 min) or temperature $\left(25^{\circ} \mathrm{C}\right)$, PVA concentration also played a critical role in the formation of discrete and stable microcrystals of $\alpha$-CD/PEG complex in PVA. The absence of crystals at higher concentrations of $\mathrm{PVA}$ is PVA $/(\alpha-\mathrm{CD} / \mathrm{PEG})=2 / 1 \mathrm{wt} \%$ solution (figure 8 ) 

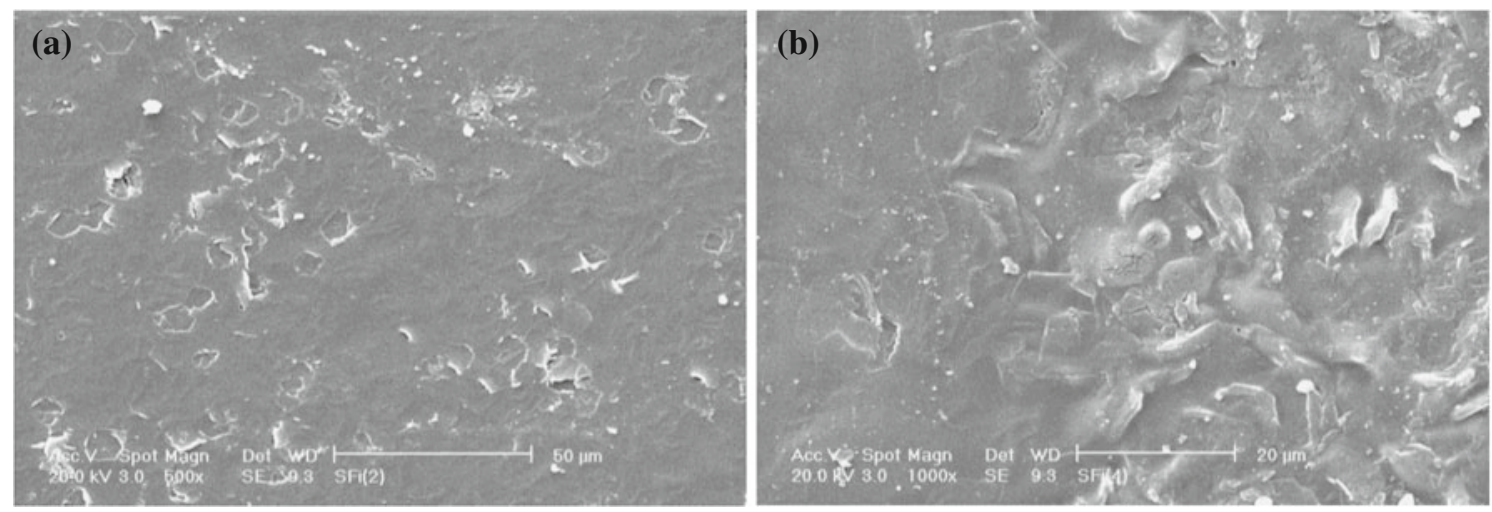

Figure 6. SEM images of effect of concentration of $\alpha-\mathrm{CD} / \mathrm{PEG}$ at a fixed concentration of PVA: (a) PVA (5\%), $[\alpha-\mathrm{CD} / \mathrm{PEG}](5 \%)$ and (b) PVA $(5 \%),[\alpha-\mathrm{CD} / \mathrm{PEG}](20 \%)$.
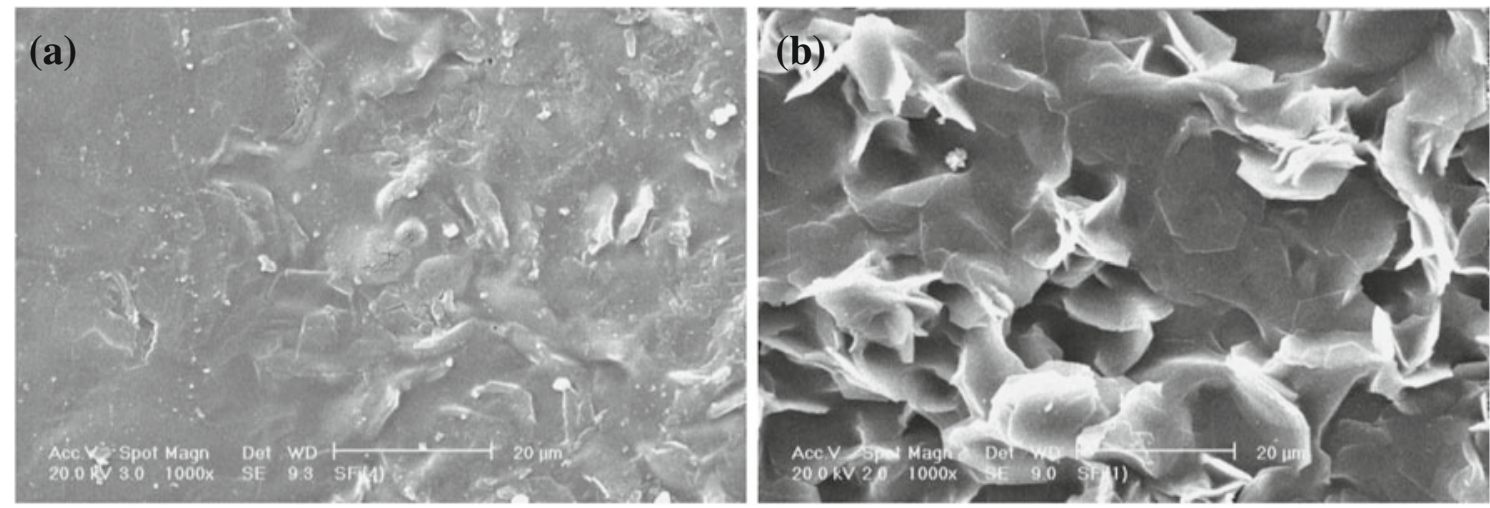

Figure 7. SEM of effect of sonication on shape of crystals: (a) PVA (5\%), [ $\alpha$-CD/PEG] (20\%), sonication time: 15 min and (b) PVA (5\%), $\alpha-\mathrm{CD} / \mathrm{PEG}](20 \%)$, sonication time: $30 \mathrm{~min}$.

Table 3. Major XRD peaks for PEG/ $\alpha-\mathrm{CD}$ in PVA complex inclusion compounds.

\begin{tabular}{lc}
\hline Sample & $2 \theta$ \\
\hline $5 \%$ PVA & $5 \cdot 385,9 \cdot 970,10 \cdot 855,17 \cdot 265,19 \cdot 760,28 \cdot 375$ \\
$20 \%(\alpha$-CD/PEG), sonic time: $30 \mathrm{~min}$ & $5 \cdot 120,5 \cdot 460,7 \cdot 655,10 \cdot 220,10 \cdot 970,44 \cdot 235$ \\
$5 \%$ PVA & \\
$20 \%(\alpha$-CD/PEG $)$, sonic time: $15 \mathrm{~min}$ & $5 \cdot 445,7 \cdot 540,10 \cdot 195,11 \cdot 005,11 \cdot 885,12 \cdot 710$, \\
$5 \%$ PVA & $16 \cdot 530,19 \cdot 840,22 \cdot 415,41 \cdot 625$ \\
$5 \%(\alpha$-CD/PEG $)$, sonic time: $15 \mathrm{~min}$ & $13 \cdot 230,17 \cdot 660,19 \cdot 875,22 \cdot 470$ \\
$(\alpha-\mathrm{CD}$ in PVA $)$ & \\
\hline
\end{tabular}

or $1 / 1$ (figure 6) can imply that a dissolution of the complex has taken place (figure $8(a, b)$ ). Microstructures of the stable complex crystals shown in figure 8(c) indicate the effect of sonication at $30 \mathrm{~min}$ or longer times on $\mathrm{PVA} /(\alpha-\mathrm{CD} /$ PEG) $=1 / 4 \mathrm{wt} \%$, where no excess PVA can be found in the solution. Figure 8 shows characteristic peaks of the new complex formed under these conditions at different times and PVA concentrations. The broad peak at $2 \theta=19 \cdot 260^{\circ}$ and a narrower one at $2 \theta=10 \cdot 85^{\circ}$ (of the film) imply that PVA solution may act like a phosphate buffer to facilitate the formation of a stable hexagonal microcrystalline complex of about $10 \mu \mathrm{m}$ dimension. The concentration and molecular weight of PVA has provided the right ionic environment for this reaction, which is stabilized by hydrogen bonding. The greater molecular weight of PVA as compared to the phosphate buffers can control the formation of a complex with higher degree of uniformity and size. The sonication has provided enough energy to overcome the viscosity effect of PVA solution in this reaction. However, the chemical potential may give enough energy to assist the dissolution of the crystalline complex at higher concentration of PVA (figure 8(a)). Furthermore, the effect of sonication time on 

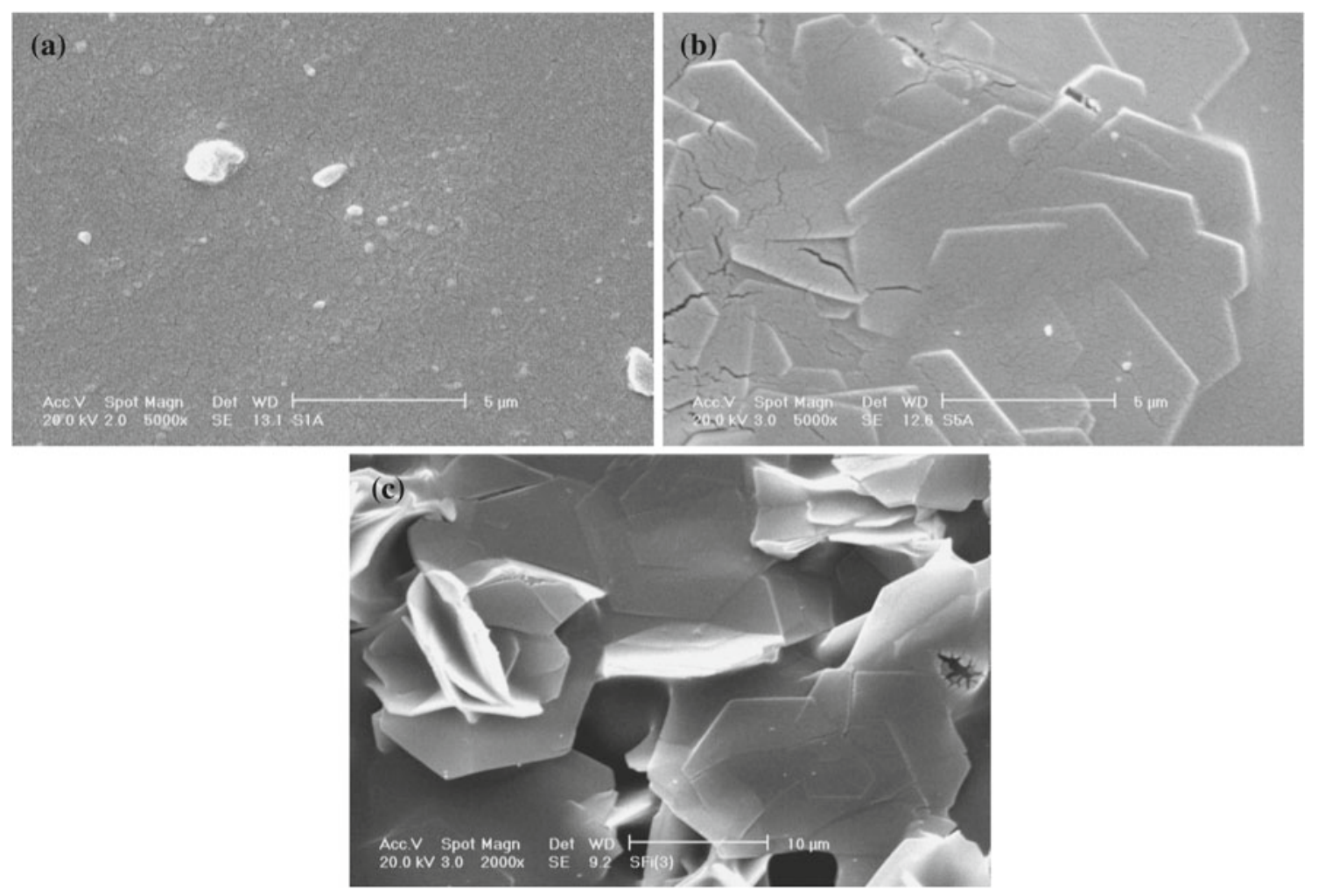

Figure 8. SEM of complex of ( $\alpha$-CD/ PEG), effect of concentration of PVA on $[\alpha-\mathrm{CD} / \mathrm{PEG}]$ at 30 min sonication: (a) PVA (10\%), $[\alpha-\mathrm{CD} / \mathrm{PEG}]$ (5\%), (b) PVA (15\%), $\alpha-\mathrm{CD} / \mathrm{PEG}](20 \%)$ and (c) PVA (5\%), $[\alpha-\mathrm{CD} / \mathrm{PEG}](20 \%)$.

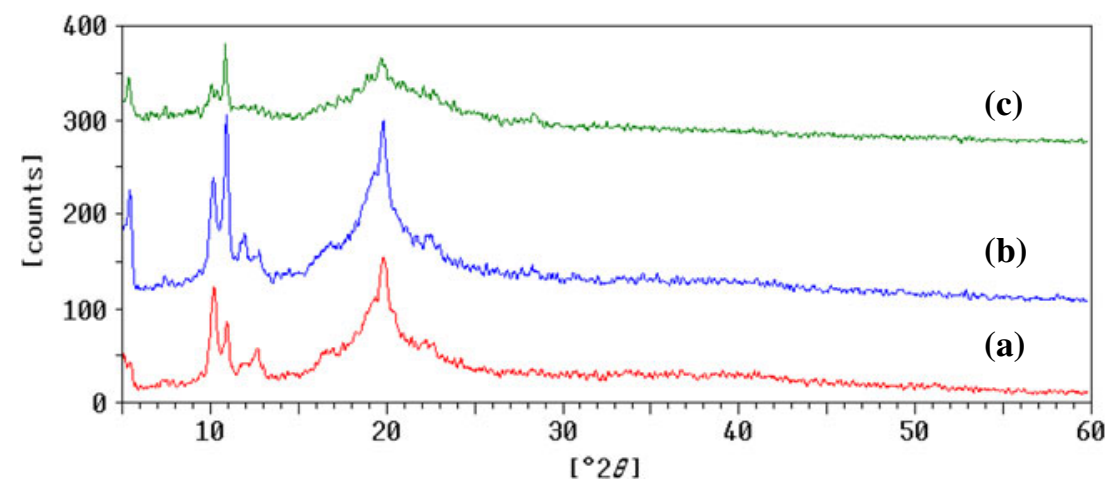

Figure 9. XRD of complex inclusions of $\alpha-\mathrm{CD} / \mathrm{PEG}$ with PVA: (a) PVA: (5\%), $[\alpha-\mathrm{CD} / \mathrm{PEG}]:(20 \%)$, sonication time: $15 \mathrm{~min},(\mathbf{b}) \mathrm{PVA}:(5 \%),[\alpha-\mathrm{CD} / \mathrm{PEG}]:(5 \%)$, sonication time: $15 \mathrm{~min}$ and (c) PVA: $(5 \%),[\alpha-\mathrm{CD} / \mathrm{PEG}]:(20 \%)$, sonication time: $30 \mathrm{~min}$.

concentration ratio of PVA introduces different microstructures (figure 9). A new complex with different characteristic peaks is reported at similar PVA/complex ratios (table 3). After 30 min of sonication, PVA ratio is far less than 1 or about 1.4 , and different inclusion complexes can be produced in this case (figure 8 and table 3 ).

\subsection{Thermal behaviour}

DSC thermograms of PEG, $\alpha-\mathrm{CD},[\mathrm{PEG} / \alpha-\mathrm{CD}]$, PVA and $[\mathrm{PEG} / \alpha-\mathrm{CD}] / \mathrm{PVA}$ polyrotaxane within temperature range of $30-+330{ }^{\circ} \mathrm{C}$ are illustrated in figure 10 . Glass transition temperature $\left(T_{\mathrm{g}}\right)$ of PEG can be observed in figure 10(a) at about $45{ }^{\circ} \mathrm{C}$ (Verheyen et al 2001; Wang et al 2004). DSC plot of $\alpha$-CD included two endothermic peaks in the temperature range of $100-110{ }^{\circ} \mathrm{C}$ due to the loss of water, while the endothermic peaks that correspond to the $\alpha$-CD near $320{ }^{\circ} \mathrm{C}$ can be additionally seen in figure 10(b) (Kawasaki et al 2007). Figure 10(c) shows $[\mathrm{PEG} / \alpha-\mathrm{CD}]$ inclusion complex with shifted peaks of $\alpha-\mathrm{CD}$ and PEG results characteristic of the microphase-separated morphology of the polymers. DSC thermograph of PVA represented a peak at $250^{\circ} \mathrm{C}$ 


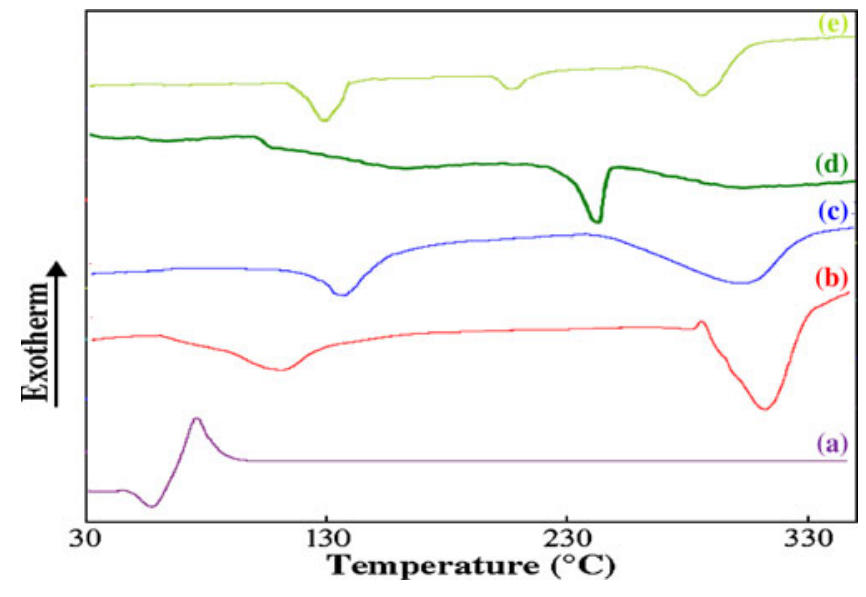

Figure 10. DSC curve of (a) PEG, (b) $\alpha$-CD, (c) $\alpha$-CD/PEG, (d) PVA and (e) PVA (15\%), [ $\alpha$-CD/PEG] $(20 \%)$ at $30 \mathrm{~min}$ sonication, from 30 to $330{ }^{\circ} \mathrm{C}$ with a heating rate of $10{ }^{\circ} \mathrm{C} / \mathrm{min}^{-1}$.

(figure 10(d)) (Agrawal and Arvind 2004). Figure 10(d) shows DSC thermograph of $[\alpha-\mathrm{CD} / \mathrm{PEG}] / \mathrm{PVA}$ with shifted peaks. Three distinct peaks at $125^{\circ} \mathrm{C}$ and $300{ }^{\circ} \mathrm{C}$ related to $\alpha-\mathrm{CD}$ and one at $220^{\circ} \mathrm{C}$ attributed to PVA have shifted from their previous location. On the basis of DSC results, one can conclude that PEG/ $\alpha-\mathrm{CD}$ and $[\alpha-\mathrm{CD} / \mathrm{PEG}] / \mathrm{PVA}$ polymers have been synthesized successfully.

\section{Conclusions}

The crystalline structures of inclusion complexes of $\alpha$ CD/PEG/PVA were studied by SEM, XRD, FTIR and HNMR. SEM images of crystals showed that sonication of the reaction in poly(vinyl alcohol) solution having different ratios of PVA/complex was utilized to develop hydroxyl groups of desired ionic strength and chain mobilities required for the formation of one new inclusion complex between $\alpha-\mathrm{CD}$ and PEG. It is possible to achieve a tricomponent inclusion compound (TIC) at similar ratios. The size of its underlying microcrystals is $\sim 10 \mu \mathrm{m}$ with almost uniform geometry. It seems that the chain mobility and presence of $-\mathrm{OH}$ groups in this process have contributed to the formation of crystals with specific geometry. The effect of sonication time on microstructure of the complex is depicted in
SEM images. Results showed that apart from sonication time (30 min) or temperature $\left(25^{\circ} \mathrm{C}\right)$, PVA concentration has also played a critical role in the formation of discrete and stable microcrystals of the $\alpha-\mathrm{CD} / \mathrm{PEG}$ complex in PVA.

\section{References}

Agrawal S L and Arvind A 2004 Bull. Mater. Sci. 27523

Araki J, Zhao C and Ito K 2004 Macromolecules 387524

Bender M L and Komiyama M 1978 Cyclodextrin chemistry (Berlin: Springer-Verlag)

Choi H S, Lee S C, Yamamoto Y and Ylli N 2005 Macromolecules 382878

Crini G and Morcellet M 2003 J. Sep. Sci. 25789

Duchene D, Ponchel G and Wouessidjewe D 1999 Adv. Drug Deliv. Rev. 3629

Harada A, Li J and Kamachi M 1993 Macromolecules 265698

Harada A, Okada M, Li J and Kamachi M 1995 Macromolecules 28 8406

Hirayama F and Uekama K 1999 Adv. Drug Deliv. Rev. 36125

Hirose Y and Otsubo Y 2008 Colloid. Surf. 31738

Horter D and Dressman J B 1997 Adv. Drug Deliv. Rev. 253

Kawasaki J, Satou D, Takagaki T, Nemoto T and Kawaguchi A 2007 Polym. Sci. 481127

Loftssona T and Duchene D 2007 Int. J. Pharmaceut. 3291

Loftssona T and Jarvinen T 1999 Adv. Drug Deliv. Rev. 3659

Matsuda H and Arima H 1999 Adv. Drug Deliv. Rev. 3681

Ohmura M, Kawahara Y, Okude K, Hasegawa Y, Hayashida M, Kurimoto R and Kawaguchi A 2004 Polymers 456967

Ooya T, Ichi T, Furubayashi T, Katoh M and Yui N 2007 React. Funct. Polym. 6 2-13

Peng F, Hu C and Jiang Z 2007 J. Membr. Sci. 297236

Saenger W 1980 Angew. Chem. Int. Ed. Engl. 19344

Semsarzadeh M A, Farhangi S and Bagheri M 2007 Using inclusion systems of cyclodextrins in formation of polymeric tube of poly(ethylene glycol) in different concentrations of buffer. ISPST 8th international seminar on polymer science and technology (Tehran, Iran: Sharif University of Technology)

Son J H, Kang Y and Won J 2006 J. Membr. Sci. 281345

Szejtli J 1982 Cyclodextrins and their inclusion complexes (Budapest: Akademiai Kiado)

Szejtli J 1998 Chem. Rev. 981743

Szente L and Szejtli J 1999 Adv. Drug Deliv. Rev. 3617

Wang X, Michoel A and Mooter G V 2004 Int. J. Pharmaceut. 272 181

Verheyen S, Augustijns P, Kinget R and Mooter G V 2001 Thermochim. Acta 380153 